\title{
Novel Aspects of Constructal Law: Four Distinct and Competing Goals in Flow Channels Design
}

\author{
Luciano Ondir Freire*, Delvonei Alves de Andrade \\ Nuclear Engineering Center, Instituto de Pesquisas Energéticas e Nucleares (IPEN-CNEN/SP), São Paulo, Brazil \\ Email: *luciano.ondir@gmail.com
}

How to cite this paper: Freire, L.O. and de Andrade, D.A. (2021) Novel Aspects of Constructal Law: Four Distinct and Competing Goals in Flow Channels Design. Open Journal of Applied Sciences, 11, 647-664. https://doi.org/10.4236/ojapps.2021.116047

Received: May 18, 2021

Accepted: June 19, 2021

Published: June 22, 2021

Copyright (c) 2021 by author(s) and Scientific Research Publishing Inc. This work is licensed under the Creative Commons Attribution International License (CC BY 4.0).

http://creativecommons.org/licenses/by/4.0/

(c) (i) Open Access

\begin{abstract}
Constructal law explains the sense of evolution (morphing to get access to flows) of finite size systems, but paradoxes do exist as not all vegetables have a tree form. Also, nature does not improve all animals for displacement. This work aims at creating a model to explain those paradoxes about constructal law. It adopted the system engineering technique of segregation between functions (abstract goals) and solutions (physical entities). Further, this work introduced the assumptions of flow under external threats and imperfect channels (subject to leakages and suboptimal form). Results showed that there are always elements doing four functions in all types of channels: to reduce entropy, to protect channel, to retain integrity and to drive flow. Although the four functions are always present, natural systems typically privilege one function over others, depending on environmental demands. As a solution to improve flows, animal brains also fit in the model of four functions. Human mind seems to have groups of instincts associated with each of the four channel design functions, leading to four behavior phenotypes and four motivations (prominence, inclusiveness, negativity prevention and tradition). Finally, this model (channels need to meet four goals) unified physics and animal psychology and extended applications of Constructal law to the fields of systems engineering methods, management, and psychological science.
\end{abstract}

\section{Keywords}

Constructal Law, System Engineering, Unifying Theory, Animal Design, Gamification, Human Centered Design

\section{Introduction}

Constructal Law states that finite-size systems morph in the sense to give greater access to the flows needed for their survival or existence [1]. Adrian Bejan [2] also told a case of the constructal law as the tendency to minimize flow resis- 
tance (or entropy generation) in a pipe for a fixed pipe length and volume. Adrian Bejan also counted the flow problems, which are: flow from point to point, flow from point to curve, flow from point to surface, flow from point to volume. The best solution for flow from point to point is the round cross section straight pipe [2]. The best solution for flow from point to a set of points (curve, surface, or volume) is a tree, which is in fact a structure composed of a set of pipes.

However, in nature, there are structures or life forms that do not seem, at first, to fit in the constructal law, like cactus (mostly a single trunk), turtles (not mobile at all) and sloths (evolved into a slow creature), as shown in Figure 1.

Recent works [3] provided more insights and examples of applications of Constructal Law in many domains, clarifying the role of hierarchy to give greater access to flows. Additionally, it also explains the role of complexity and freedom in creation of diversity. Constructal Law is fully falsifiable and testable and has been applied successfully in thousands of works [4], either explaining design of existing systems (human-made or not) or providing a basis to define an optimization objective.

Yet, some apparent contradictions exist, and one may be confused about where to start when applying Constructal Law, as sometimes the objective is to reduce entropy in thermal exchange and sometimes it is the contrary. This work aims at creating a model to explain such singularities or paradoxes by adding the assumptions of flow risks and pipe imperfections. The novelty of this work is to provide a quantifiable set of goals that a designer needs to address for most situations, without recurring to Ad Hoc considerations. This contribution is in the intersection of physics and system engineering and extends the applications of Constructal Law to fields of systems engineering methods, management, and psychological science.

\section{Materials and Methods}

The first step is to show these work assumptions:

Every aspect of design serves to the constructal law statement: beings morph to improve flows.

The elementary channel is the base to solve every flow problem (point to point, point to curve, point to surface, and point to volume) as trees are also composed of straight channels.

The environment of the flow system has sources of disturbances or threats
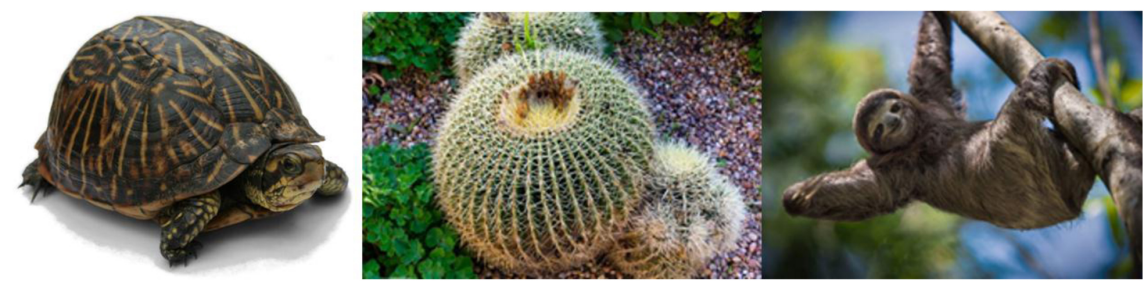

Figure 1. Examples of beings which do not seem to adhere to constructal law. 
that may cause total or partial flow interruption. Examples are attacks from predators (for animals) and natural phenomena for inanimate, like a land slide that blocks a river.

Imperfections are always present in pipe construction. The system cannot achieve a perfect round form in practice, nor perfect tightness, as order requires energy application (perfect form requires infinite energy).

Probabilistic approach: threats events and intensities are not deterministic but occur following a probability density function. The same goes for the channel construction, as construction methods (natural or human made) never perfectly replicate the forms.

Real-life flow systems (for instance, animals) may need simultaneous flows to exist, like water, food, sun bath, sex.

A single flow interruption may destroy the system. For instance, block of airways for animals.

Formal segregation of goals and solutions. Goals are abstract intentions or finality in design. System engineering, as value engineering [5], always presents functions (goals) in a two-word abridgment consisting of an active verb and measurable noun (what is being done to the verb, and what it is being done to the noun). On the other hand, solutions are material entities with physical properties like mass, volume, dimensions. Such separation gives freedom (to system designers) to search for better solutions (more added value) for the stated goals.

Flows may be displacement of fluids (like air, water), electric charge (like in electric power transmission), energy (like heat or mechanical work), force (like structures or fluid pressure or mechanical stress) or information (low power signals above environment noise that transmit data).

Newton's laws of mechanics apply to the systems that this work address. Nowadays, there are cases where Newton laws do not apply, like particles physics, but this work does not include such cases.

This work method uses the systems engineering approach, consisting of the following steps:

Definition of the volume under study. For [6], a system is a division of the perceived world in two parts: one internal and other external. From the inner part there are outputs and from the outer part there are inputs.

Identification of relations with the rest of the world. Such relations are the functions (goals) the system must achieve and the demands of the inner part of the system from the external part.

Identification of the domains to evaluate the hypothesis (like fluid, mechanical, electrical, for example).

Identification of the solutions performing each function foreach domain.

Figure 2 presents the summary of methodology adopted for this study in a

Assumptions $\rightarrow \begin{gathered}\text { Definition of } \\ \text { volume under } \\ \text { study }\end{gathered} \rightarrow \begin{gathered}\begin{array}{c}\text { Identification of } \\ \text { relations with } \\ \text { environment }\end{array}\end{gathered} \rightarrow \begin{gathered}\text { Identification } \\ \text { of domains } \\ \text { for test }\end{gathered} \longrightarrow \begin{gathered}\text { Identification } \\ \text { of solutions }\end{gathered}$

Figure 2. Summary of methodology this work adopted. 
graphical way.

\section{Development}

The control volume is the generic channel, which is an arbitrary volume in space where a fluid goes from point A to point B. From the assumption of segregation of functions (goals) and solutions, this work expresses all required and enough conditions (to set up a flow in a channel) in the form of "action verb + measurable noun." From the assumption of threats existence, there is need of protection against external aggressions. From the assumption of imperfections, there is need of solutions to mitigate leakages before the fluid reaches point B. From the existence of viscous forces and constructal Law statement, channels need to minimize the entropy generation, reducing the charge losses. From Newton's first law of motion (inertia) and the existence of viscous forces, the flow needs a driving force to occur. Taking the enumerated assumptions into account, to set up flow from one point to other, the following functions are necessary:

To reduce entropy. This function is the goal of reducing entropy generation or power requirements of the flow, as Bejan states [2]. This means to increase the amount of useful energy. Due thermodynamics second law, every movement implies in entropy generation. Fluid systems irreversibly lose part of their energy due the viscosity property. For fluids, a solution for this function is the round shape of pipes. For electric charges, a solution is to use materials with high electrical conductibility. For force transmission, the solution is to use materials with low damping and high frequency of resonance. For energy, a solution is to use materials with high thermal conductibility. In the case of human readable information, a solution is to employ simple language, also called principle of minimum surprise.

To drive flow. This function is the goal of driving the flow once the natural tendency is to stay still in steady state because movement increases entropy. For instance, differences of potential drive electric charges on power lines; pressure differences drive fluid flows; or increasing hydraulic fluid working pressure.

To protect channel. This function is the goal of keeping the availability of the channel volume for the flow, preventing plugging caused by an external aggression. This function is a response to the assumption of external threats. An example is a protective shell against external aggressions. Anti-corrosion coatings are examples of protection of mechanical structures. Anti-noise measures, like twisting pairs and shielding cables are examples of solutions to protect information flows; and

To retain integrity. This function is the goal of reduction of average loss of part of the flow content in time or keeping the same flow at inlet and outlet. Forms cannot be perfect by assumption, so a channel needs to mitigate losses or leaks over time, as such losses usually evolve over time. As in dynamic systems definition of stability (tendency to return to a point or region of the space-state), this function tries permanently to bring back the channel to a perfect form 
(content loss equal to zero), which is in fact impossible. An example is electric insulation on electric cables or thermal insulation for thermal machines. Integrity check is a common solution to know if a message is corrupt. For force transmission, the solution is to use materials with high rigidity.

It is interesting to note in Figure 3 the presentation of the four functions of the channel, where the vertical axis is related to flow availability and the horizontal axis relates to exergy (useful energy).

As for the hypothesis check, the authors decided to take only twelve economically interesting examples, as an exhaustive analysis in nature would be impractical. Therefore, the analysis considered the following domains:

Fluid: pipes conducting fluids like air or water.

Electric: electric cables conducting electricity.

Mechanical: structures conducting either force, movement, positioning, or mechanical stress.

Thermal: systems conducting heat from one point to other.

Information: media conducting information by signals. Signals may be light, electrical, pneumatic, mechanical or any other kind.

Functional analysis: characterization of a single basic function of a system, either in value engineering or system engineering sense.

System engineering methods: global characterization of a system to meet the needs of customers, also known as top-down analysis [7].

Real time software: algorithms processing a set of input data to output critical information.

Vegetables: the design of vegetables to conduct a set of fluids.

Animal body: design of animal bodies to conduct a set of fluids.

Animal mind: observable human phenotypes in games; and

Enterprises: human organizations that buy a set of resources, transform them, and sell to a set of customers.

\section{Results}

This section presents the results of analysis of checking whether the hypothesis of the four functions really exist for each chosen domain, pointing the physical solutions.

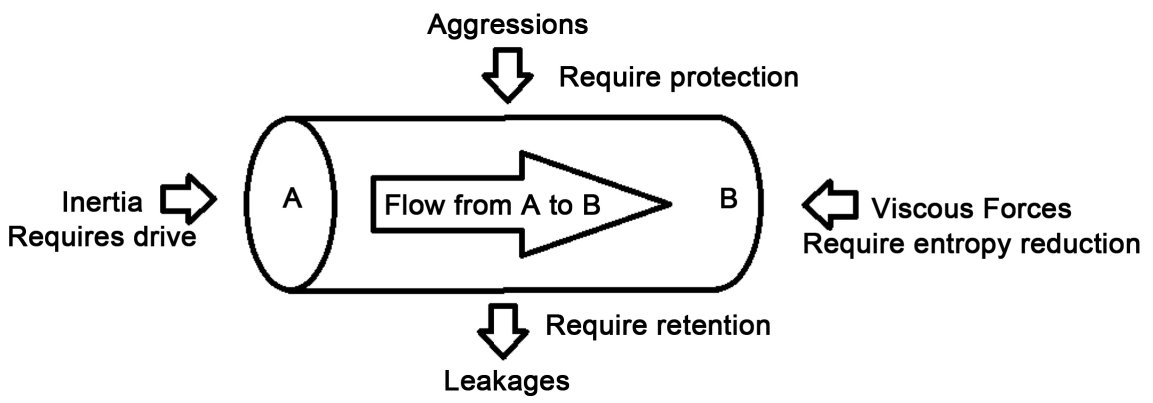

Figure 3. Analysis of a generic channel: necessary and enough conditions to set a flow from point $\mathrm{A}$ to point $\mathrm{B}$. 
In fluid domain, to reduce entropy is to reduce the charge losses. Both natural and human made systems typically do this by adopting pipes with circular cross-section. In cases where the intent is to send power, like in hydraulic systems, increasing the working pressure also reduces the charge losses by using less fluid. To drive the flow, systems create pressure differences between origin and destination points, typically by pumps or gravity. Systems protect the channel volume by adopting rigid pipes (like animal air ways) or by internal pressure (arteries are flexible but sustain their inner volume by their internal pressure). In case of rigid pipes, the system uses also other domain: mechanical domain, whose flow is mechanical stress. There is a special case, the river where a combination of gravity and terrain properties do the protection of the channel. Finally, fluid systems also have solutions to retain integrity, like use of air-tight or watertight materials for pipe walls. Besides the basic material, systems use solutions to make tight joints and to restore tightness. Animal bodies have healing capabilities to stop blood losses and human-made systems use welding, brazing, rubber seals, seal tapes to keep tightness. This means that to retain integrity, as important as to be initially tight by design, there is need to restore tightness upon a failure.

In electric domain, architects reduce entropy generation by reducing the heat losses. Typically design reduces current flow (increasing tension), uses materials with high conductivity and increases conductor's cross-section. Electrical potential differences drive electricity through cables and usually generators do this function. The most usual protection to electrical transmission lines are fuses and circuit breaker, given short circuit is the main danger. Another usual protection is lightning protector, who serves not only to protect transmission lines but anything. To retain integrity, electrical conductors use insulation, reducing electric leakage currents. Further, operators check periodically the insulation to restore it.

In mechanical domain, a structure may send mechanical power, like a shaft, a time variant position, like a robotic arm, or a force, like a ball bearing (it applies radial forces to a shaft to keep it in place). As matter of word limitation, authors chose only the simplest case (the ball bearing). In this case, to reduce entropy means to reduce mechanical losses due friction. The bearing housing drives the force flow into the bearing, meaning the seat housing is the source of the force that keeps the shaft in place. As bearings are usually metallic, corrosion is the main issue. Besides, the wear is also a problem. Lubricants address both aggressions, increasing life of ball bearings. The integrity in this case is the required force to keep the shaft centered, meaning that a perfect bearing would be inelastic, which is impossible in practice. Therefore, to retain integrity, bearing design adopts materials with high stiffness and shapes that reduce flexibility. A more precise approach would be to use an active bearing with position feedback.

Thermal domain is also vast, including conducting walls, fins, and heat exchangers. In this domain, to reduce entropy is to reduce the resistance to heat 
propagation, because this resistance decreases the temperature and useful energy of heat. Solutions are to employ high thermal conductibility materials, increase contact surface, decrease wall length, and increase heat transfer coefficients. Temperature differences drives the heat flow as second law of thermodynamics predicts. Therefore, when the need is to introduce energy in a system, design needs a hot source, usually a fluid with higher temperatures, like combustion gases heat water. When the need is to remove heat from a system, the solution is to use a cold source, like sea water or river water. To protect the channel is usually to prevent fouling as nature tend always to create deposits of low conductivity materials on heat exchange surfaces. Solutions to prevent fouling are to clean surfaces periodically, use high speed flows, use materials or coatings that prevent deposition. The content in this domain is energy in form of heat and it has the tendency to leak to environment. To keep the heat, systems use thermal insulation.

In information domain, to reduce entropy is to reduce required energy to make a valid bit of information go from origin to destination. The reason is information systems require power but do not produce work by themselves, producing only entropy. As typically information systems work at constant power, reducing entropy means reducing message content, or compress information. Solutions are to use media with low attenuation, low power processors and to compress information. To drive the information flow, systems need power supply, typically electric power supply in human made systems. In the other hand, animal brains also have information channels powered by glycose, as every live cell. Noise may prevent information flow and there are solutions to reduce noise, like shielding cables, use of robust signals (current is more robust than tension), use of twisted pairs and digital filters. Despite noise reduction measures, data loss or corruption may occur. Measures like integrity check and handshakes help to keep the information flow integrity.

In functional analysis domain, a function requires a set of flows, for instance, a cooling water system has the function of removing heat and it has an outward cold-water flow and an inward hot water flow. To reduce the lifecycle cost of a function is to reduce entropy, as money is proportional to effort or work spent to get the function done. The need of driving flows determines the function performances or flow intensities. The need of protecting flows affects function robustness to external aggressions, like shocks, temperature, water, powder, electromagnetic noise, radiation, and mechanical pressure. The need of retaining integrity (or restoring the flow integrity) affects both repair rates (or maintainability) and reliability (Mean Time Between Failures-MTBF or its inverse, the failure rates).

In the domain of system engineering methods, a function specification is a set of information (requirements) about one function and specifications need to flow inside a design team. To reduce entropy, specifications (being information or messages) need to reduce the number of words and to employ words and 
language constructs that require little time to understand (same as information). To drive the information flow, people should produce specifications within deadlines (time response). To protect the information flow, management should impose rules against ambiguous words, irrelevant information, and contradictory or unfeasible requirements (noise in process). A solution to do that is to impose a rigid syntax for requirements, like "property" must be "comparator" "value" "unit." Another solution is to have independent reviewer to check if requirements are workable and use often used words. To keep integrity of information, management should retain in mind the necessary purpose of the project and require specifications to be complete. A fundamental tenet of a value methodology is that design must preserve the information about basic functions (the necessary purpose of the project) [5]. Once value is proportional to the ratio between the function (action done to the interests of customers) over resources (money invested) [5], forgetting about basic functions leads to commercial failures. So, keeping the function (instead of previous solutions) in mind is the most fundamental aspect, but is not enough. Completeness means that specifications have requirements (along verification methods) about the four goals for each function:

Largest acceptable lifecycle cost;

Minimum acceptable performance;

Minimum acceptable robustness; and

Smallest acceptable availabilities.

In software domain, particularly in real time software, there are four important properties that the software must have: predictability, time response, robustness, and stability. Predictability means that the software makes the system behave always in the same way, regardless of the input or internal states. Time response (maximum time elapsed between input and output) is the most famous property for real time software, so that most people believe that time response alone defines real time software. Robustness means the software can supply correct answers even facing partial failures or receiving part of inputs wrong. Stability means the software keeps its properties over time, preventing rare logical events like stack overflow, memory overflow, deadlocks and livelocks. In the view of authors, predictability relates to entropy, as increasing predictability reduces entropy. Time response requirements are constraints on flow drive, or amount of information overtime the software must give (also smallest bandwidth constraint). Robustness requirements, like resistance to a single hardware failure, protect the flow of information against external threats or input noise. Robustness depends on architecture and usual solutions are redundancy, diversity, and segregation. The content for software is the procedure intended by the programmer and described in source code and stability requirement retains the integrity over the life cycle of the software. It is important to note that software stability also depends on development process, as newer versions may introduce issues that did not exist. 
In vegetables domain, trees adopt a hierarchy both to roots and canopy to reduce charge losses (entropy generation) in water and nutrients flow. Bejan [2] demonstrated that the best shape (with minimum charge losses) to convey a flow from a point (the tree trunk) to a volume (the canopy volume where photosynthesis occurs or root volume where water is absorbed) is a tree. To drive flows, for instance water from roots to leaves, trees use a set of forces, like capillary effect and osmotic pressure [8]. To protect the flows against large herbivore animals, plants usually have thorns, which is a type of mechanical defense. Plants also produce herbicides to aid in resource competition against other plants, which is a process known as allelopathy. Allelopathy also targets herbivore animals, contributing to plant species survival and propagation. Plants also have strategies to retain integrity (content being water and nutrients). Plants may drop leaves to reduce water loss in case of drought, or plants in arid regions develop forms with reduced surface to volume ratio, which helps to keep water.

In domain of animal bodies, to reduce entropy is to reduce the amount of energy for displacement. Besides the flows inside the animal body (which uses round cross section) animals also need to move the entire body to get access to food, water, air, and sex. Their bodies, according to their scale, evolved to the best forms [9]. In animals, the solution to drive flows are muscles, both internally (heart acts as pump) and externally (arms and legs drive the animal to flow sources). Animal bodies may have shells and hardened skins to protect their flow channels against predators' aggressions. Alternatively, animals may use speed and sharp senses to evade predators or use horn or thorns to counterattack predators. In other cases, animals may use claws and fangs to defend themselves, meaning that there are attacks in nature with the function to protect flows. The content the animal bodies need to keep are nutrients, water, and heat. Usually, their skin plays a key role by supplying a fluid-tight surface and fur insulates heat. In terms of water retention, kidneys play a key role in species that need to survive dry environments.

In mind domain, the analysis becomes more complex as psychological theories are based on personal observations, like Sigmund Freud psychoanalytic theory. From this work standpoint, animal minds (including human mind) should have the four functions, lest the animal dies because of lack of flows. For example, to reduce entropy, we should have a desire to spend less effort to do a task or to have an innate curiosity to find new ways of doing things. Alternatively, social animals should have wishes to cooperate, as tasks sharing eases life through specialization and teamwork. An instinct to get things would be a consequence of the function to drive flows, so animals would eat even without hunger, play to make exercises, become stronger, and to accumulate tools or money. Fear would be a solution to protect the channels inside the body, leading animals to avoid danger, where danger means any kind of flow interruption, like starvation, hypothermia, and physical integrity. Attachment would be a solution to retain integrity, leading animals to want to keep social relations, social status, things, 
places, and anything that directly or indirectly contributes to flows. It soon becomes clear that it is easy to produce a convincing psychological theory, however, in science, we need empirical evidence. If all those four functions are necessary to survival, human population should have a perfect balance between the four goals. However, making use of stochastic assumption, in everyone, only one goal would be dominant, and the others would be recessive, manifesting only in extreme situations. For instance, a very greedy person will act on basis of fear if a dangerous situation appears. This means that behavior phenotypes should be four and only four and their proportion should be near one quarter in population. In hundreds of games in an experiment run in Spain [10] in 2016, an algorithm (unsupervised clustering procedure, the K-means clustering algorithm) found four player phenotypes (optimist, pessimist, envious and trustful). Authors believe this finding is quite relevant because there is not human subjectivity in the classification. It is interesting to note that researchers did not find any purely rational phenotype, which would seek the maximum expected profit, as economists assume people behave. It is interesting to note that there are people who seem to decide randomly, but they are a minor part. Although all phenotypes are near $25 \%$, envious phenotype (30\%) is almost two times more abundant than trustful (17\%). Table 1 presents the human phenotypes along the assumed relation with the four functions.

Last, but not least, in the domain of enterprises, the concept of constructal law is not new for economists, as Pfeffer and Salancik first stated the resource dependency theory in 1978 [11]. Besides profit (that is obviously the main driver

Table 1. Human behavior phenotypes [10].

\begin{tabular}{|c|c|c|c|c|}
\hline $\begin{array}{c}\text { Phenotype } \\
\text { name }\end{array}$ & $\begin{array}{c}\text { Phenotype } \\
\text { objective }\end{array}$ & Proportion & $\begin{array}{l}\text { Dominant } \\
\text { function }\end{array}$ & Comments \\
\hline Optimist & $\begin{array}{l}\text { Maximizes } \\
\text { maximum } \\
\text { payoff }\end{array}$ & $20 \%$ & $\begin{array}{l}\text { To drive } \\
\text { flow }\end{array}$ & $\begin{array}{l}\text { Those players choose the option } \\
\text { with maximum potential gain, } \\
\text { even if it is unlikely, like in lottery. } \\
\text { They seem focused in increasing } \\
\text { the flow drive. }\end{array}$ \\
\hline Pessimist & $\begin{array}{l}\text { Maximizes } \\
\text { minimum } \\
\text { payoff }\end{array}$ & $21 \%$ & $\begin{array}{c}\text { To protect } \\
\text { flow }\end{array}$ & $\begin{array}{l}\text { Those players avoid any situation } \\
\text { where there is potential loss. They } \\
\text { seem focused in flow protection. }\end{array}$ \\
\hline Envious & Retain status & $30 \%$ & $\begin{array}{l}\text { To retain } \\
\text { integrity }\end{array}$ & $\begin{array}{l}\text { Those players seem to avoid a } \\
\text { relative loss, neglecting the } \\
\text { absolute gain. They seem focused } \\
\text { in keeping status or equality. }\end{array}$ \\
\hline Trustful & $\begin{array}{c}\text { Cooperates } \\
\text { always }\end{array}$ & $17 \%$ & $\begin{array}{l}\text { To reduce } \\
\text { entropy }\end{array}$ & $\begin{array}{l}\text { Those players always keep playing, } \\
\text { seeming to focus in get more } \\
\text { information. }\end{array}$ \\
\hline Undefined & $\begin{array}{l}\text { Decides } \\
\text { randomly }\end{array}$ & $12 \%$ & None & $\begin{array}{l}\text { May be those players were not } \\
\text { motivated, did not understand the } \\
\text { game or they simply have perfectly } \\
\text { balanced instincts. }\end{array}$ \\
\hline
\end{tabular}


for organizations, analogous to the function of driving the flow in channels), this theory states that organizations seek freedom, stability, and certainty in their resource's exchanges. Freedom in this context means that management may start or end an activity at own discretion, and commitment with an external actor (person or organization) is loss of freedom. If an organization depends completely on another for a critical resource, this dependency may lead to rise in prices and reduction of profit margins. Therefore, lack of freedom in resource dependence theory has analogy with entropy generation. Certainty in resource exchange is the inverse of probability of failure to obtain a critical resource or to sell a product and relates to flow protection. Finally, stability in resources exchanges is, in the opinion of authors, to retain integrity of the flow of goods, for instance, without losses, market prices fluctuations, and quality changes. Technically speaking, stability requires quality control, configuration management and capability maturity in the sense of CMMI [12].

As a result, Table 2, summarizes the findings for all domains.

Table 2. Examples of functions across domains.

\begin{tabular}{|c|c|c|c|c|}
\hline Domain & to reduce entropy & $\begin{array}{l}\text { to protect } \\
\text { channel }\end{array}$ & $\begin{array}{l}\text { to retain } \\
\text { integrity }\end{array}$ & to drive flow \\
\hline Fluid & reduce charge loss & $\begin{array}{l}\text { sustain } \\
\text { channel } \\
\text { volume }\end{array}$ & $\begin{array}{l}\text { set and restore } \\
\text { tightness }\end{array}$ & $\begin{array}{l}\text { create pressure } \\
\text { difference }\end{array}$ \\
\hline Electric & reduce heat losses & $\begin{array}{l}\text { prevent short } \\
\text { circuits }\end{array}$ & $\begin{array}{l}\text { prevent leakage } \\
\text { currents }\end{array}$ & $\begin{array}{l}\text { create electric } \\
\text { potential } \\
\text { difference }\end{array}$ \\
\hline Mechanical & $\begin{array}{l}\text { reduce mechanical } \\
\text { losses }\end{array}$ & $\begin{array}{l}\text { prevent } \\
\text { corrosion }\end{array}$ & reduce flexibility & house bearing \\
\hline Thermal & $\begin{array}{l}\text { reduce heat } \\
\text { resistance }\end{array}$ & reduce fouling & $\begin{array}{l}\text { reduce heat losses } \\
\text { to environment }\end{array}$ & $\begin{array}{l}\text { create } \\
\text { temperature } \\
\text { difference }\end{array}$ \\
\hline Information & $\begin{array}{l}\text { reduce spent } \\
\text { energy per bit }\end{array}$ & reduce noise & reduce data loss & supply power \\
\hline Function & limit cost & $\begin{array}{l}\text { define } \\
\text { robustness }\end{array}$ & define availability & $\begin{array}{l}\text { define } \\
\text { performance }\end{array}$ \\
\hline Method & $\begin{array}{l}\text { ease } \\
\text { communication }\end{array}$ & prevent noise & $\begin{array}{l}\text { retain } \\
\text { information }\end{array}$ & define deadline \\
\hline Software & $\begin{array}{l}\text { require } \\
\text { predictability }\end{array}$ & $\begin{array}{l}\text { require } \\
\text { robustness }\end{array}$ & require stability & $\begin{array}{l}\text { define time } \\
\text { response }\end{array}$ \\
\hline Vegetables & reduce charge losses & $\begin{array}{l}\text { prevent } \\
\text { attacks }\end{array}$ & retain fluids & $\begin{array}{l}\text { Drive water } \\
\text { and nutrients }\end{array}$ \\
\hline $\begin{array}{l}\text { Animal } \\
\text { body }\end{array}$ & $\begin{array}{l}\text { reduce energy for } \\
\text { displacement }\end{array}$ & $\begin{array}{l}\text { protect against } \\
\text { aggression }\end{array}$ & $\begin{array}{l}\text { keep fluids, } \\
\text { nutrient, and heat }\end{array}$ & drive movement \\
\hline $\begin{array}{l}\text { Animal } \\
\text { mind }\end{array}$ & seek cooperation & $\begin{array}{l}\text { maximize } \\
\text { minimum } \\
\text { payoff }\end{array}$ & retain status & $\begin{array}{l}\text { maximize } \\
\text { maximum payoff }\end{array}$ \\
\hline Enterprises & seek freedom & manage risks & seek stability & make profit \\
\hline
\end{tabular}




\section{Discussion}

This section discusses about imprecisions and limits to the model of four functions, adding extra considerations and reserves.

About limits and scope, authors found no exception to the presence of those functions in every observed flow. But there are cases in which the solution performing a function is not a material, but a force like gravity or osmotic pressure. For example, riverbed shape and gravity prevent bounders to obstruct rivers (protect the channel); hoses and arteries use internal pressure to prevent obstruction.

At results section, examples of systems with simultaneous flows follow elementary examples of single flow channels, but development section analyses only the elementary channel. Yet it is valid because even the most complex flow system is a composition of elementary flow channels and the proposed examples give evidence of validity. Authors believe it is easy to prove by absurd that the four functions are necessary:

1) Without a force driving the flow, inertia and viscous forces stop the flow.

2) The occurrence of an obstruction coming from outside would stop the flow.

3) Leakages can prevent the flow of arriving at the destination point.

4) Complex or inadequate shape may virtually stop the flow due charge loss (entropy generation).

However, it is necessary to prove that only those four functions are necessary (meaning that they are sufficient and there is not any other function), despite it seems evident. The works on human psychology [10] [13] are scientifical evidence of the completeness of the four functions, as the respective authors used sound mathematical methods to identify the phenotypes or motivations without assuming a given number a priori. The OODA and PDCA processes and configuration management functions also are practical evidence of the number of only four goals, although other cycles with other numbers also exist, so it is a weaker evidence. Assuming cylindrical coordinates and axial symmetry (radial angle becomes irrelevant) as Figure 4 shows, one can find there are only four relevant pressures for design.

One may state that there are only two types of directions (radial and axial) and four senses (inward, outward, forward, backward). The outward pressure tends

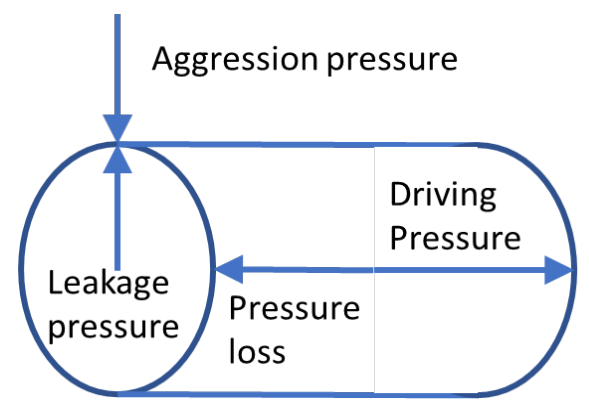

Figure 4. Complete representation of all relevant pressures in cylindrical coordinates. 
to cause leakages and need solutions to retain integrity of the flow. The eventual inward pressure due to aggression needs solutions to protect the availability of space for the flow, remembering that two bodies cannot occupy the same space. The pressure caused by the viscous forces (typically named pressure or charge loss) needs minimization to improve the flow. The flow system needs a solution to create a driving pressure, which enters in equilibrium with the pressure loss.

Some may find that the exhaustiveness (of this list of pressures) is a logical or mathematical proof that there are only four relevant goals in design of fluid systems. Other types of systems should have similar or analog demonstrations, so the four goals could be consequence of geometry and known physical laws, so one can rationally deduce them as a pure thought exercise like the mathematical definition of system [6]. However, it is not pure mathematics of system engineering because it considers Isaac Newton laws, Thermodynamic laws, and Construtal Law. Therefore, this work is in the intersection between physics (models of reality) and system engineering (system thinking, formal distinction of goals and solutions). It is a model of reality because it helps to explain the natural designs and it is a contribution to system engineering because it proposes and justifies a necessary and sufficient set of class of measures in system engineering methods. Besides that, this work identifies a necessary and sufficient set of classes of requirements for each function.

This work did not enter in detail about class of measures or requirements because each project needs Ad Hoc tailoring. The external threats, tendency to information loss, precision of information about client's needs and lifecycle costs are variables that change completely the best solution. For instance, robustness requirements could be less important in domestic equipment than military equipment, so the first could give little attention to shock requirements (saving effort) but the latter needs extensive care with robustness. Some industries need little information about client needs, like basic food, but others need a large set of information about client desires, like gaming industry. Inelastic demand items, like basic food, should reduce price as much as possible, but highly elastic demand items, like luxury objects, should care less about costs. Retaining integrity should be more important for critical embedded software than for gaming industry. At each case one must balance the effort with the marginal returns, so this work does not provide a solution, but a complete set of goals that may require effort according to the situation. Designers should spend the minimum effort to improve the flow in the average expected case, avoiding oversizing.

Although all four functions are always present, environment may impose more mass and energy investment in one function than the other functions. When this happens, there is a dominant function while the other three stay recessive. Table 3 presents examples of natural systems design according with the respective dominant functions.

In human mind, which this work assumed as a solution to get access to flows (food, shelter, water, breeding), the existence of four types of players is shown to be empirically confirmed. But players types are different of functions, that if 
Table 3. Examples of natural systems and their dominant functions in design.

\begin{tabular}{ccccc}
\hline \multirow{2}{*}{$\begin{array}{c}\text { Natural system } \\
\text { type }\end{array}$} & $\begin{array}{c}\text { to reduce } \\
\text { entropy }\end{array}$ & $\begin{array}{c}\text { to protect } \\
\text { channel }\end{array}$ & $\begin{array}{c}\text { to retain } \\
\text { integrity }\end{array}$ & to drive flow \\
\cline { 2 - 5 } & large trees & thorn tree & cactus & grass \\
Vegetables & birds & turtle & camel & horse \\
Animals & trustful & pessimist & envious & optimist \\
Player types & & & & \\
\hline
\end{tabular}

correct as developed, those functions are all necessary and enough, meaning all of them need to be present in design. If there was a dominant function in human mind, only one type of player would appear. A perfectly balanced mind is impossible (assuming perfect balance, like perfect shape, would require too much energy to build), so, individuals have a dominant goal in mind. This model has the merit to propose an explanation to the clear irrationality of all players, being rationality the act of seeking expected profit. Yet the developed model and the game experiment [10] present consistency, there is also a deviation: the function to retain integrity (not losing relatively to the other player) is dominant in the population. On the opposite, the function to reduce entropy generation seems underrepresented in the human population. As this is a single experiment in an event in a country, it is impossible to know if this distribution is culturally or genetically induced. The empirical article claims that gender and age do not change the distribution, suggesting the proportion is quite general. If such distribution is universal, it may mean that people are twice more prone to keep current ideas and behaviors than seeking new ways of doing things.

Another evidence of the presence of the four goals is the PINT (Prominence, Inclusiveness, Negativity prevention, and Tradition) taxonomy of human goals [13]. This work, using answers of thousands of people about what they are investing money or effort, came to conclusion that those four classes of goals achieved the best fit for data. Although this study seems somewhat subjective, it is also data-driven and based on language analysis, giving a solid evidence that the human mind is an evolutive response the four functions. In this case, the search for prominence is related to the function of "driving flow" and leads to an optimistic, risk taking behavior. Inclusiveness seems to relate to the function of "reducing entropy" by the cooperation and specialization and leads to the trustful behavior. Negativity prevention clearly leads to a pessimist behavior and is probably consequence of the function of "protecting channel". While the desire of preservation of tradition relates clearly to the function of "retaining integrity", the least obvious relation is between the preservation of tradition and envious behavior. But if one assumes that envy is a consequence of attachment to a social position, it becomes clear that to retain integrity in social structure, one must avoid loss of affection or loss of relative position in hierarchy. In capitalist societies, money is the prime driver of hierarchy between people, so the desire for integrity drives people to not get behind others, while trying to keep the ancient 
ways. In practice, this drive for tradition may prevent innovation, particularly those that are disruptive (disruptive is a technology that provides a huge economical advantage to the adopter). This means people which have a huge desire for retaining integrity (tradition) tend to suffer when it becomes clear that a new technology or behavior is superior to the currentone. This could explain why a person which values tradition does not keep a game where the other player gains more because it feels like the beginning of a disruption of order. Therefore, desire for retaining integrity or tradition could lead to an innate tendency for communist practices, where all receive equal shares, explaining why such practices (or advocates of such practices) are recurrent in history.

This model of human mind may have implications to enterprise organization, as it is easy to identify the player type by group dynamics and management should allocate functions according to the player type. Prominence seekers should lead projects, inclusiveness seekers should work in innovation management or public relations, negativity prevention-oriented people should work with safety or security, and tradition seekers should work on quality. Envious people could kill any innovation, optimists could ignore risks, trustful people could bring chaos to quality management and pessimists would avoid any ambitious projects.

There are other parallels of the four functions, like John Boyd's OODA(Observe, Orient, Decide, Act) loop, applicable to combat operations, military strategy, law enforcement and business. The loop is a set of loops continuously interacting during combat. Observation is the raw information the sensors provide, and it relates to the function of keeping stability, assuring all relevant information is kept. Orientation is the filtering of raw information to ease the next loop activities and relates to reduction of entropy. Decision considers the perceived value of an alternative in relation to others and typically adopts a trained doctrine to enhance speed to avoid defeat. As this loop is critical to avoid the negative scenarios of defeat, it has a close relation to protection function. Finally, the Action loop is the interaction with the environment and relates to the function of driving the flow.

Another iterative four step method is (Plan, Do, Check, Act) PDCA cycle (Shewhart or Deming cycle), applicable to management. It starts the "Plan" that involves the definition of goals and methods and seems related with the function to protect the channel, as it defines the structure and includes risk management. The second step is "Do", meaning carrying out the methods to achieve the goals, which relates to the function of driving the flow. The third step is "Check", meaning comparison of measured results and defined goals, along identification of trends ("Check" relates to the function of retaining integrity). The "Act", also called "Adjust" is a step of process improvement, involving the identification of structural problems, inefficiencies, and other issues. This step also gives origin to proposals to improve the process to avoid recurrence of problems. As it aims at improving overall efficiency, this step is clearly related to the function of reducing entropy. 
Table 4. Comparison of loops, cycles, or functions.

\begin{tabular}{ccccc}
\hline \multirow{2}{*}{ Cycle } & \multicolumn{4}{c}{ Constructal function in design } \\
\cline { 2 - 5 } & $\begin{array}{c}\text { to protect } \\
\text { channel }\end{array}$ & to drive flow & $\begin{array}{c}\text { to retain } \\
\text { integrity }\end{array}$ & $\begin{array}{c}\text { to reduce } \\
\text { entropy }\end{array}$ \\
\hline OODA & Decision & Act & Observe & Orient \\
PDCA & Plan & Do & Check & Act \\
Config. Manag. & Control & Identification & Auditing & Status accounting \\
\hline
\end{tabular}

In system engineering, there is also the four configuration management functions: configuration control, configuration identification, configuration status account, and configuration auditing. Configuration is the information about the composition of a system, like a list of parts, and in complex systems where many people work, there is need of a set of rules to authorize creation, modification, and deletion of items. Such rules are the configuration control function and avoid the insertion of false data on the database, protecting the workflow from noise and defining a structure to the work. The configuration identification is the creation of the data, the final goal of the process, and drives the workflow. The problem is errors tend to accumulate over time and to keep their quantity acceptable, periodically the database needs auditing to retain integrity over time. To ease the general process, each configuration item needs to have its history recorded along the justifications for changes, avoiding recurrence of problems and reducing the disorder (or entropy).

It is interesting to note that all those empirical methods, seemingly to be independently developed for distinct applications (military, business management, or systems engineering), have four simultaneous processes. Moreover, all of them have similar meaning for each process and timely sequence is the same, changing only the start of the cycle. This work suggests this is not coincidence as may seem, but a necessary consequence of Constructal Law, as Table 4 shows the relation to the four functions.

Reader may find the statement of constructal law vague as it relies on adverbs like "easier" and "greater" changing the words "access to flows." So, what is a quantifiable definition of "greater access to flows"? This work proposes it is to reach simultaneously the four functions and only these four functions. The generated entropy in a system is quantifiable in entropy units. The driving force also is quantifiable in Newtons. The protection of the flow is also quantifiable in robustness requirements, like shock levels, electromagnetic compatibility, temperature, pressure, water, radiation, and corrosion. Integrity is quantifiable in failure rate and in restoration rate, leading to system availability.

\section{Conclusions}

Systems thinking helped to clarify apparent paradoxes in constructal law. After adding the assumptions of presence of threats, imperfections, and degradations on channel forms, need of driving force, it becomes clear that flows need more 
than entropy reduction. To set up a flow, it is necessary and enough that design achieves the following functions: reduce entropy; protect channel; retain integrity; and drive flow.

The analysis of functions (goals) of the elementary channel included the identification of particularities for a set of domains. This work presented a finite induction from twelve domains, relating the proposed functions with the physical solutions. The model of four functions is adherent to simple channels and even complex systems which need a considerable number of simultaneous flows. Additionally, such model is fully objective and quantifiable, supplying a complement to the statement of constructal law.

A key finding was that addressing the four functions for every flow channel of a product is necessary to prevent unforeseen costs at later life stages.

Another key finding is that this model also may explain why empirical research shows that players are not rational (do not seek to maximize the expected gain) but seek four different goals. This way, the four functions model extends physics (Constructal Law) to psychology.

Economical application to this model may include engineering design, engineering methods, information systems design (human centered design or gamification), game industry, politics (law making).

Future work consists of exploring human mind drives in engineering information systems using human-centric design (gamification techniques). Such an approach may improve productivity and personnel satisfaction.

When four goals or types are present in a model (strategy, management, configuration management, software development, psychology, etc.), it is not a coincidence or an Ad Hoc aspect of a single discipline: it is a physical consequence of constructal law. Additionally, it seems organizations need to set 4 groups of simultaneous processes where data flows cyclically in this specific order (not necessarily starting at this point) with the goals of protecting channel, driving flow, retaining integrity, and reducing entropy. This means this work also extended Constructal Law applications to the field of organizational management.

Therefore, this work belongs simultaneously to the field of physics and to the field of system engineering.

\section{Conflicts of Interest}

The authors declare no conflicts of interest regarding the publication of this paper.

\section{References}

[1] Bejan, A. and Lorente, S. (2013) Constructal Law of Design and Evolution: Physics, Biology, Technology, and Society. Journal of Applied Physics, 113, Article ID: 151301. https://doi.org/10.1063/1.4798429

[2] Bejan, A. (2003) Thermodynamic Formulation of the Constructal Law. Proceedings of the ASME 2003 International Mechanical Engineering Congress and Exposition, 
Washington DC, 15-21 November 2003, 163-172.

https://doi.org/10.1115/IMECE2003-41167

[3] Bejan, A. (2020) Freedom and Evolution: Hierarchy in Nature, Society and Science. Springer Nature, London. https://doi.org/10.1007/978-3-030-34009-4

[4] Errera, M.R. (2018) Constructal Law in Light of Philosophy of Science. Proceedings of the Romanian Academy, Series A, 111-116.

[5] The Save International the Value Society (2007) Value Standard and Body of Knowledge. 33.

https://wsdot.wa.gov/sites/default/files/2014/09/22/WhatIsValueEngineering.pdf

[6] Wymore, A.W. (1993) Model-Based Systems Engineering. CRC Press, Boca Raton.

[7] Blanchard, B.S. and Fabrycky, W.J. (2011) System Engineering and Analysis. 5th Edition, Prentice Hall International Series in Industrial and Systems Engineering, New Jersey, 786.

[8] Niklas, K.J. and Spatz, H.-C. (2014) Plant Physics. University of Chicago Press, Chicago, 448 .

[9] Bejan, A. (2016) The Physics of Life: The Evolution of Everything. St. Martin's Press, New York.

[10] Poncela-Casasnovas, J., et al. (2016) Humans Display a Reduced Set of Consistent Behavioral Phenotypes in Dyadic Games. Science Advances, 2, e1600451. https://doi.org/10.1126/sciadv.1600451

[11] Pfeffer, J. and Salancik, G.R. (2003) The External Control of Organizations: A Resource Dependence Perspective. 2nd Edition, Stanford University Press, Stanford.

[12] Software Engineering Institute (2011) CMM Acquisition V1.3 Quick Reference Guide.

https://resources.sei.cmu.edu/asset_files/TechnicalReport/2010_005_001_15284.pdf

[13] Wilkowski, B.M., et al. (2020) Lexical Derivation of the PINT Taxonomy of Goals: Prominence, Inclusiveness, Negativity Prevention, and Tradition. Journal of Personality and Social Psychology, 119, 1153-1187. https://doi.org/10.1037/pspp0000268 